\title{
Auditory Compensation for Early Blindness in Cat Cerebral Cortex
}

\author{
Josef P. Rauschecker and Martin Korte ${ }^{a}$ \\ Laboratory of Neurophysiology, National Institute of Mental Health, Poolesville, Maryland 20837 and Max-Planck-Institut für \\ biologische Kybernetik, D-7400 Tübingen, Germany
}

\begin{abstract}
Single-neuron activity was recorded in the caudal part of the anterior ectosylvian (AE) cortex of cats that had been deprived of vision for several years by means of binocular lid suture shortly after birth and in normal control animals. Over 300 neurons were tested in each group with auditory, visual, and somatosensory stimuli.

We confirmed the existence of an anterior ectosylvian visual area (AEV) in the fundus and ventral bank of the AE sulcus. Neurons in AEV had purely visual responses in normal cats. In visually deprived cats, by contrast, only a minority of cells in this area still responded to visual stimulation. Instead, most cells reacted vigorously to auditory and, to some extent, somatosensory stimuli. The few remaining visual neurons were also driven by auditory or somatosensory stimuli. No increase in the number of unresponsive neurons was found. It appears, therefore, that a cortical region that normally represents visual activity can become driven by auditory or somatosensory activity as a result of visual deprivation.

Our results imply that early blindness causes compensatory increases in the amount of auditory cortical representation, possibly by an expansion of nonvisual areas into previously visual territory. In particular, they provide evidence for the existence of neural mechanisms for intermodal compensatory plasticity in the cerebral cortex of young animals. The changes described here may also provide the neural basis for a behavioral compensation for early blindness described elsewhere.
\end{abstract}

[Key words: cross-modal plasticity, visual deprivation, sensory compensation, multimodal processing, anterior ectosylvian cortex]

The visual cortex of young cats has been one of the major systems for the study of neural plasticity in the developing brain ever since the days when Wiesel and Hubel (1963) performed their first lid-suture experiments. Subsequently, a host of studies have demonstrated the dependence of the visual cortex on sensory experience during a critical period for normal development

Received Jan. 4, 1993; revised Apr. 20, 1993; accepted May 6, 1993

We thank Robert Gelhard for technical assistance, Markus Lappe for help with programming, Biao Tian and John Olsen for help with recording and stimulus design, and Laurence Harris, Alex Meredith, and Steve Wise for helpful comments on the manuscript.

Correspondence should be addressed to Josef P. Rauschecker, LNP, NIMH, P.O. Box 608, Poolesville, MD 20837.

"Present address: Max-Planck-Institut für Psychiatrie, D-8033 München-Martinsreid, Germany.

Copyright (C) 1993 Society for Neuroscience $0270-6474 / 93 / 134538-11 \$ 05.00 / 0$ (see Rauschecker, 1991, for a recent review). What most of these studies have shown is the extreme vulnerability of the young cortex, if experience is withheld: visual neurons become less selective or even unresponsive to visual stimuli with continuing visual deprivation (Wiesel and Hubel, 1965; Singer and Tretter, 1976). Only to a limited extent has it been demonstrated that there is actual adaptation of cortical response properties to unusual environments (Blakemore and Cooper, 1970; Stryker et al., 1978; Rauschecker and Singer, 1981). Some authors have wondered, therefore, what the survival value of developmental plasticity is for the individual, if it mainly risks the deterioration of cortical representations (Pettigrew, 1978). An obvious solution to the dilemma would be if other brain systems profit from the deprivation in one sensory modality. Indeed, evidence for such intermodal compensation has been presented, if sparsely, in some instances (Vidyasagar, 1978; Hyvärinen et al., 1981; Rauschecker and Harris, 1983; Carlson et al., 1987; Rauscheckcr ct al., 1992). What has yet to be demonstrated, however, is how extensive such compensatory plasticity can be, and where at the cortical level it can be shown most convincingly.

It appears from the studies on superior colliculus (SC) of visually deprived animals (Vidyasagar, 1978; Rauschecker and Harris, 1983) that brain structures with input from more than one modality might have the best chance to show compensatory changes after early deprivation. In the present study of intermodal plasticity in cerebral cortex we concentrated, therefore, on a region in the anterior ectosylvian (AE) cortex, where different sensory modalities are known to coexist (Fig. $1 A, B$; Berman, 1961; Carreras and Andersson, 1963; Reinoso-Suárez and Roda, 1985). A visual area (anterior ectosylvian visual, AEV) has been identified in the ventral bank and fundus of the AE sulcus (Mucke et al., 1982; Olson and Graybiel, 1983, 1987; Norita et al., 1986; Benedek et al., 1988), and a somatosensory area (S IV) has been described more rostrally (Clemo and Stein, 1983). In addition, an auditory field exists in the caudal part of the AE sulcus ("field AES"; Clarey and Irvine, 1986, 1990a,b). We will refer to this area as AEA (anterior ectosylvian auditory area) by analogy with AEV. Area AEA also provides the main source of auditory cortical input to the SC (Meredith and Clemo, 1989; Clarey and Irvine, 1990b). Unlike in the deep layers of the SC, however, the degree of multimodal convergence has not been determined unequivocally in the $\mathrm{AE}$ sulcal region: some studies found largely unimodal responses (Clemo and Stein, 1983; Clarey and Irvine, 1986; Norita et al., 1986; Olson and Graybiel, 1987; Meredith and Clemo, 1989), whereas others found a high proportion of multimodal neurons (Minciacchi et al., 1987; Clarey and Irvine, 1990a; Jiang et al., 1990). Another goal of this study was therefore to determine the amount of multimodal overlap in AE cortex. 
These results have been previously presented in abstract form (Rauschecker and Korte, 1992).

\section{Materials and Methods}

\section{Animals}

Four cats with binocular visual deprivation (BD) and two normal control cats of comparable age were studied. At the time of recording the cats were between 4 and 10 years old. Their external meatus were examined and found to be normal and clean. Visual deprivation had been achieved by means of lid suture at $10 \mathrm{~d}$ of age and continued without interruption. Lid suture was performed under ketamine anesthesia $(25 \mathrm{mg} / \mathrm{kg}$ bodyweight, i.m.) and followed standard procedures (Wiesel and Hubel, $1963,1965)$. The lids were reopened at the beginning of the electrophysiological study after anesthesia had been induced, and the optic media were found to be unaffected in all animals. The eyes remained open until all study was completed and the animal was killed for histology.

\section{Single-unit recording}

All cats were prepared for repeated extracellular single-unit recording in semichronic experiments, in order to obtain a complete mapping of the anterior ectosylvian region in each animal. Recording chambers and a stainless steel head bolt were implanted on the animals' skull in a single aseptic surgery under gas anesthesia. Halothane (1-2\%) or isoflurane $(1.5-2.5 \%)$ was used in a 50/50 mixture of nitrous oxide/oxygen while the animal was intubated and ventilated with a Harvard respirator. Body temperature, EKG, and expiratory $\mathrm{CO}_{2}$ were constantly monitored and kept within the physiological range. Intravenous intusion of dextrose $(5 \%)$ in saline $(0.9 \%)$ was given throughout the surgery. A small craniotomy was performed under the recording chamber while the dura was left intact. After the chamber was put in place with orthopedic bone screws and sterile bone cement, the skin around it was sutured shut, and all wounds were treated with an antiseptic. Systemic injections of antibiotics and analgesics were given postoperatively for several days.

Between 2 and 10 recording sessions, each lasting 5-10 hr, were subscquently performed under nitrous oxide/oxygen $(70 / 30 \%)$ with halothane $(0.6 \%)$ or isoflurane $(1.0 \%)$. The same physiological parameters were controlled and intravenous infusions were given during recording as during surgery. Muscle paralysis was not used except for the precise mapping of visual receptive fields, when eye movements had to be eliminated. During these periods, the cats were temporarily paralyzed with a pulse of pancuronium bromide $(0.05 \mathrm{mg} / \mathrm{kg})$, which has a halflife of only a few minutes. During these brief intervals, the EKG was monitored particularly closely, in order to assure adequate levels of anesthesia. If any changes in heart rate were noted in response to noxious stimuli, the concentration of anesthetic gas was increased.

Lacquer-insulated tungsten microelectrodes were used, which were inserted through the dura and into cortex with a hydraulic microdrive. Neuronal spike activity was recorded from single neurons in the AE region of the cerebral cortex between Horsley-Clarke coordinates $\mathrm{A} 10$ and A13 (Fig. $1 C$ ). Electrode penetrations were evenly spaced by $0.5-$ $1.0 \mathrm{~mm}$ along the mediolateral dimension between L10 and L14. Neurons in the AE sulcal region (areas AEA and AEV) were always sampled at a distance of $250 \mu \mathrm{m}$ along the track, whereas in the AE gyrus the sampling interval was sometimes $500 \mu \mathrm{m}$ (see Figs. 2, 5). Neurons in the AE gyrus consistently responded only to auditory stimuli, and it was clear from functional criteria that they were part of the anterior auditory field (AAF): they responded well to pure tones and were organized in a tonotopic fashion (Knight, 1977; Merzenich et al., 1982; Tian and Rauschecker, 1992). In all animals, the left hemisphere was studied in semichronic recordings. In the normal cats, the right hemisphere was studied in addition in a final terminal recording session under the same conditions, and some additional recordings were performcd in a more anterior region of $\Lambda \mathrm{E}$ cortex between $\Lambda 13$ and $\Lambda 18$. Routinely, two or more microlesions were made along all electrode tracks for later reconstruction by passing DC current $(7 \mu \mathrm{A}$ for $7 \mathrm{sec})$ through the electrode.

Action potentials were sent through a "slicer" unit, which selectively amplifies all transients above a certain amplitude, thereby enhancing the signal-to-noise ratio, and then through a window discriminator. Thus, spikes of different amplitude could always reliably be discriminated. The resulting trigger pulses were then transferred to a 386 personal computer for data collection. Raster displays and peristimulus time histograms (PSTHs) were generated and evaluated in response to various forms of sensory stimulation. A bin width of $1 \mathrm{msec}$ was routinely used for recording, and stimulus presentation was repeated 20 times. For display purposes, bin widths of up to $10 \mathrm{msec}$ were used.

\section{Sensory stimulation}

Visual stimulation. For the mapping of visual receptive fields a tangent screen was placed $57 \mathrm{~cm}$ in front of the cat. Retinal landmarks (blind spot and area centralis) were projected on the screen by means of a fundus camera (Zeiss). Computer-generated visual stimuli were backprojected on the tangent screen with a video projector. Conventional light and dark bars or spots were used, as well as specially designed flow-field stimuli (Brenner and Rauschecker, 1990). The latter covered an area of $100 \times 70$ degrees $^{2}$ and could expand, contract, or rotate in synchrony with data collection.

Auditory stimulation. Auditory stimuli were presented in a normal laboratory environment. Near free-field conditions in the large $(4.7 \times$ $7.6 \mathrm{~m}$ ) recording room were found for the sound field measured at the location of the cat's head: a Bruel \& Kjaer (B\&K)-type 4133 (free field) $1 / 2$ inch microphone and a B\&K Precision Sound Level Meter 2235 (A-weighting scale), which employs a "ront-mean-square" procedure, were used for measurement of sound levels. A B\&K 4230 Sound Level Calibrator $(1 \mathrm{kHz}, 94 \mathrm{~dB})$ was used for calibration of the sound meter. We measured a drop in sound intensity of $6 \mathrm{~dB}$ with a doubling of the distance between the sound source and the microphone. The sound level at the position of the cat's head was measured for source directions from $60^{\circ}$ left to $60^{\circ}$ right in $20^{\circ}$ steps, at the elevation of the cat's ears and a speaker-to-microphone distance of $1 \mathrm{~m}$. The data showed that sound level was independent of source direction over this range. Our measurements revealed the presence of echoes with a minimum delay of $16 \mathrm{msec}$ and an attenuation of at least $15 \mathrm{~dB}$ with respect to the incident wave.

Stimuli consisted of tone bursts, produced by an analog waveform generator (Wavetek 148A), which were gated to a $50 \mathrm{msec}$ duration with a $5 \mathrm{msec}$ rise/fall time applied by a control unit (HI-MED, HG $300 \mathrm{G}$ ). Intensity was controlled with an attenuator built into the Wavetek that was calibrated with the B\&K Sound Level Meter. In addition, a standard set of seven different complex stimuli was created as follows. Our preliminary studies, as those of others (e.g., Clarey and Irvine, 1990a), had shown that most neurons in AEA greatly prefer certain natural sounds, such as finger snapping, hand clapping, key jingling, hissing, or kissing sounds, over pure tones. What all these preferred natural stimuli have in common is a broad frequency spectrum and a short duration. In order to generate a standard test battery, a number of such natural sounds were recorded with a condenser microphone (Sony ECM-150T) and digitized on a 486 personal computer with the SIGNAL program package (Engineering Design, Belmont, MA); seven of these sounds were eventually used for study. Thus, the time signals and spectra of these complex stimuli were well defined and constant throughout the study. Their sound levels were measured and calibrated with the B\&K Sound Level Meter in the "I" setting for impulsive sounds. Sound levels during stimulation were computer controlled from the SIGNAL program in steps of $5 \mathrm{~dB}$ and were increased from $5-25 \mathrm{~dB}$ above the steady background level $(52 \mathrm{~dB})$ until the response was maximal and well above threshold. Actual sound intensities used ranged between 57 and $77 \mathrm{~dB}$ SPL at the position of the cat's head.

All stimuli were played to the animal via a high-fidelity power amplifier (Hafler SE 120) and a single high-fidelity speaker (Infinity Kappa 5 ), whose frequency response was flat $( \pm 6 \mathrm{~dB})$ between 0.4 and $24 \mathrm{kHz}$, as measured with a $1 / 2$ inch microphone (B\&K 4133). The speaker was mounted on a movable stand and placed, successively, in seven different equally spaced azimuthal positions $1.14 \mathrm{~m}$ from the cat's head, directed straight toward it, between $-60^{\circ}$ (ipsilateral to the recorded hemisphere) and $+60^{\circ}$ (contralateral). Speaker elevation was always at the height of the cat's ears.

Somatosensory stimulation. Somatosensory stimuli were delivered either with a fine brush or with an air-puff device (Neurophore Pneumatic Pump Module), whose solenoid valve could be triggered in synchrony with the 386 computer for the assembly of PSTHs. The air puff was delivered through a narrow tube with its opening held close to the animal's skin, so that only a small area $\left(\sim 1-2 \mathrm{~mm}^{2}\right)$ was stimulated. The exerted pressure was low (1-2 kg/ $\mathrm{cm}^{2}$, as set at the pump module), so only cutaneous receptors were likely to be activated. Great care was taken not to confuse the somatosensory response to air puff with an auditory response to the sound of its delivery by repeating air-puff stimulation away from the animal's body. 
A

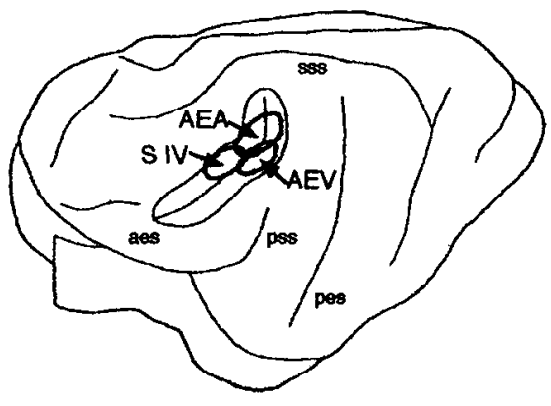

$\mathbf{B}$

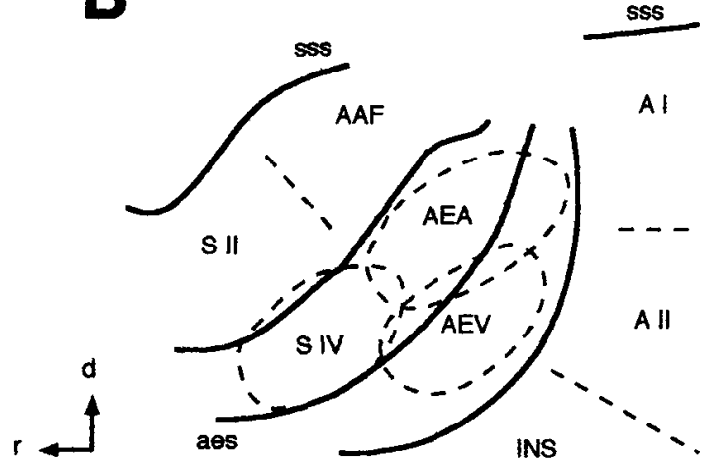

Figure 1. Region of $\mathrm{AE}$ cortex from which neuronal activity was recorded in the cat's brain. A, AE sulcus (aes) opened up showing approximate sites of subdivisions with different sensory preferences, as described in this and previous studies. An anterior ectosylvian visual area $(A E V)$ is found on the ventral bank and fundus of the AE sulcus (from Olson and Graybiel, 1987); an anterior ectosylvian auditory area $(A E A)$ is found in its fundus and both banks, but mainly dorsally ("field AES" of Clarey and Irvine, 1986, 1990a; Meredith and Clemo, 1989). The somatosensory area $S I V$ of Clemo and Stein (1983) lies in the anterodorsal aspect of the AES. sss, suprasylvian sulcus; pss, pseudosylvian sulcus; pes, posterior ectosylvian sulcus. $B$, Close-up of sensory representations in the caudal part of the AE region. Zones of overlap are indicated, in which a higher incidence of multimodal neurons can be expected. $A A F$, anterior auditory field on the AE gyrus; $A I$, primary auditory cortex; $A$ $I I$, "secondary" auditory field; $I N S$, insular cortex; $S I I$, second somatosensory area. $d$, dorsal; $r$, rostral. $C$, Planes of coronal sections (1-4), as shown in Figures 2 and 5 , through the $A E$ region, in which data were collected. $l s$, lateral sulcus. Scale bar, $1 \mathrm{~mm}$.

C

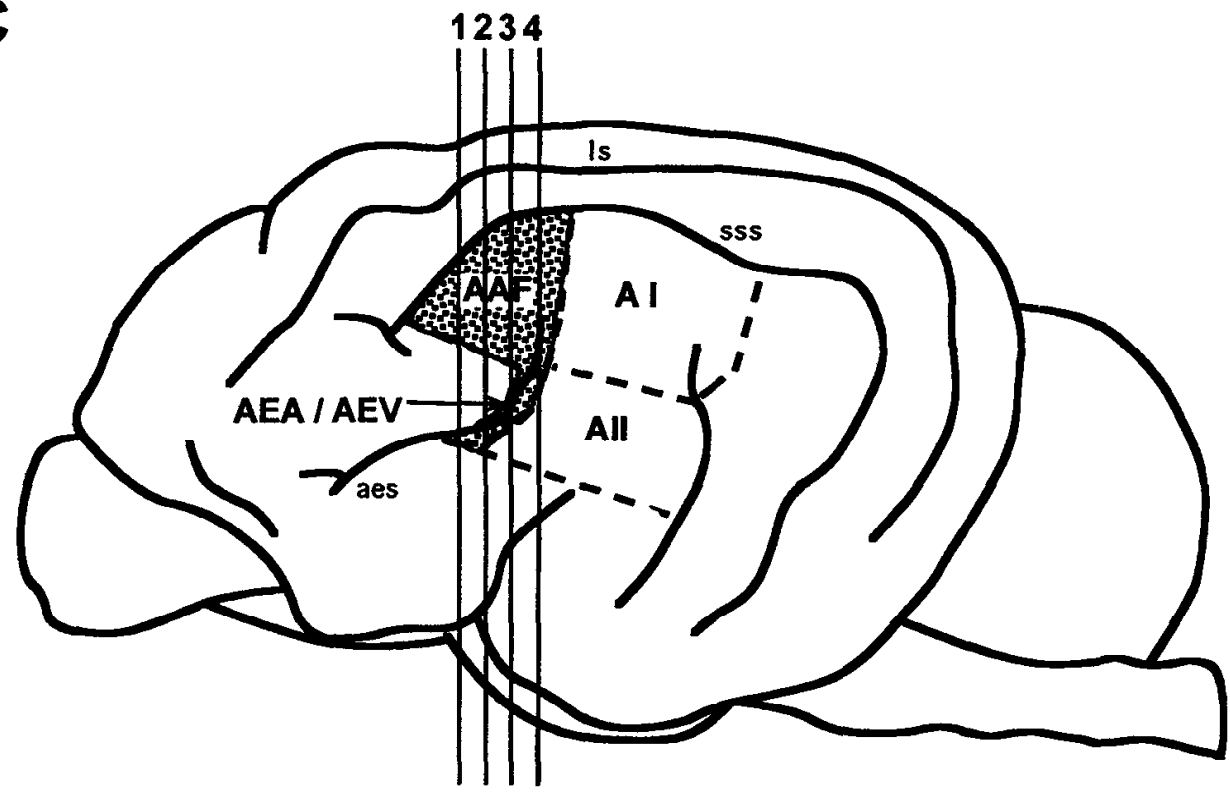

rostral
H $1 \mathrm{~mm}$
Nonresponsive neurons. As a fourth class of neurons (with great importance for statistical purposes), unresponsive neurons were identified as well. Such neurons were detected by monitoring their spontaneous activity, but they could not be driven by any of the sensory stimuli employed, even after extensive attempts. Since this still does not exclude that these cells would not be responsive to yet other types of stimuli, perhaps even in another modality (e.g., vestibular or olfactory), the cautious term "no clear response" (NCR) was used to characterize them. The anesthetic regimen, which may also have an influence on the responsiveness of $\mathrm{AE}$ neurons, was of less concern in the present study, because we compared animals studied under the same conditions. However, the effects of anesthesia may be important to consider when data are compared between different studies.

\section{Histology}

After the end of an experiment, which consisted of at least two recording sessions, the animal was given an overdose of Nembutal and perfused with formalin $(10 \%)$. The brain was removed from the skull and stored in a mixture of formalin and saccharose (30\%) for several days. Frontal sections through the AE region were cut at $50 \mu \mathrm{m}$ and Nissl stained with cresyl violet. Electrode tracks were reconstructed between $A 10$ and A13. The electrolytic lesions made during recording sessions were used for reconstruction, and a linear shrinkage factor of $85-90 \%$ was taken into account.

\section{Statistical data evaluation}

The proportions of visual, auditory, and somatosensory as well as the percentage of unresponsive (NCR) neurons in the AE sulcal region of control and $\mathrm{BD}$ cats were compared using the nonparametric, distribution-free $\chi^{2}$ test for independent samples.

\section{Results}

Modality specificity in the AE sulcus of normal cats

Previous studies have yielded conflicting results on the amount of multimodal convergence in single neurons of the AE sulcal region. The first aim of this study was therefore to determine the proportions of visual, auditory, and somatosensory responses in normal adult cats.

Sensory modality was analyzed in 621 neurons of the caudal AE region between Horsley-Clarke coordinates A10-A13. Electrode track reconstructions from four hemispheres in two cats 

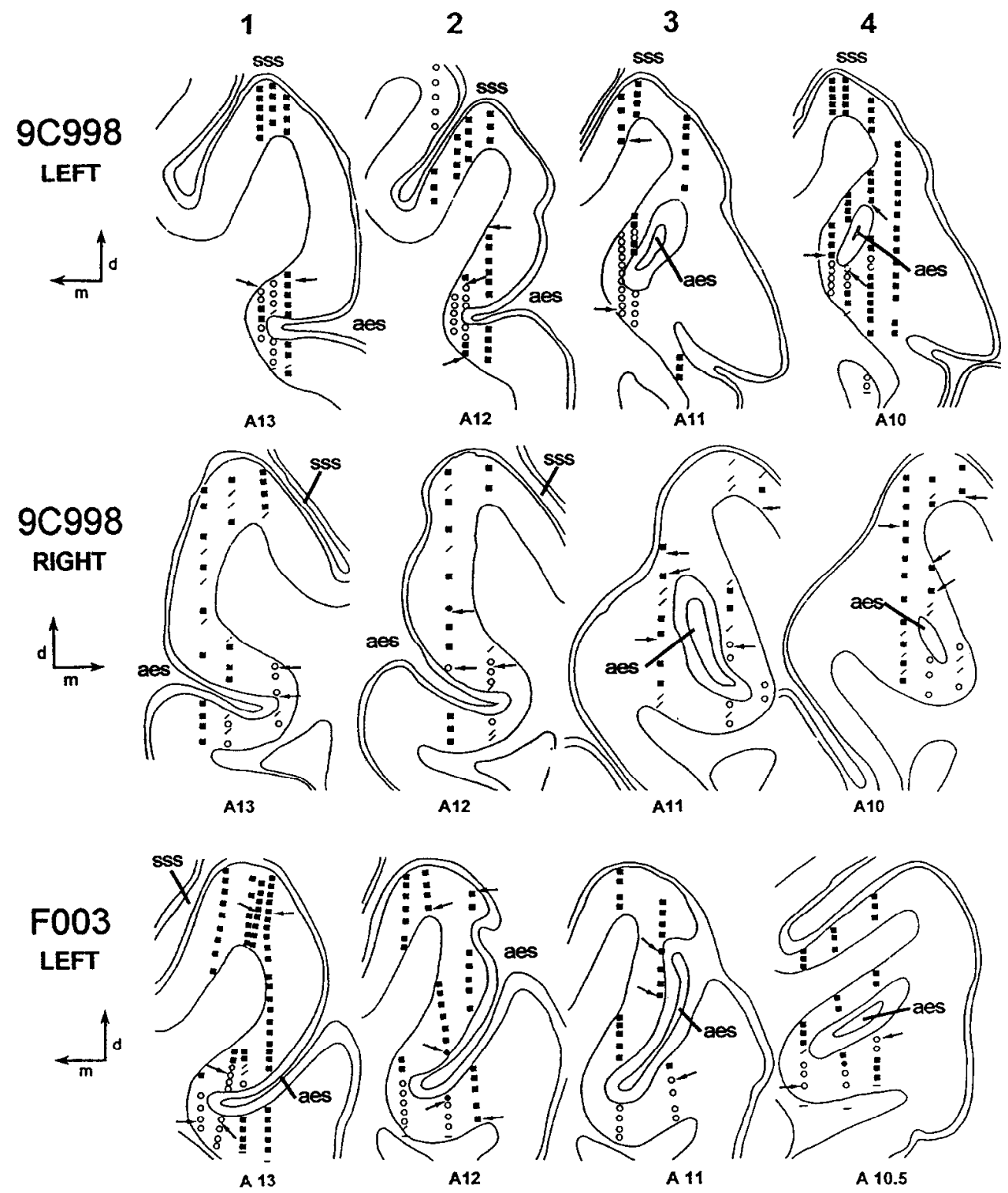

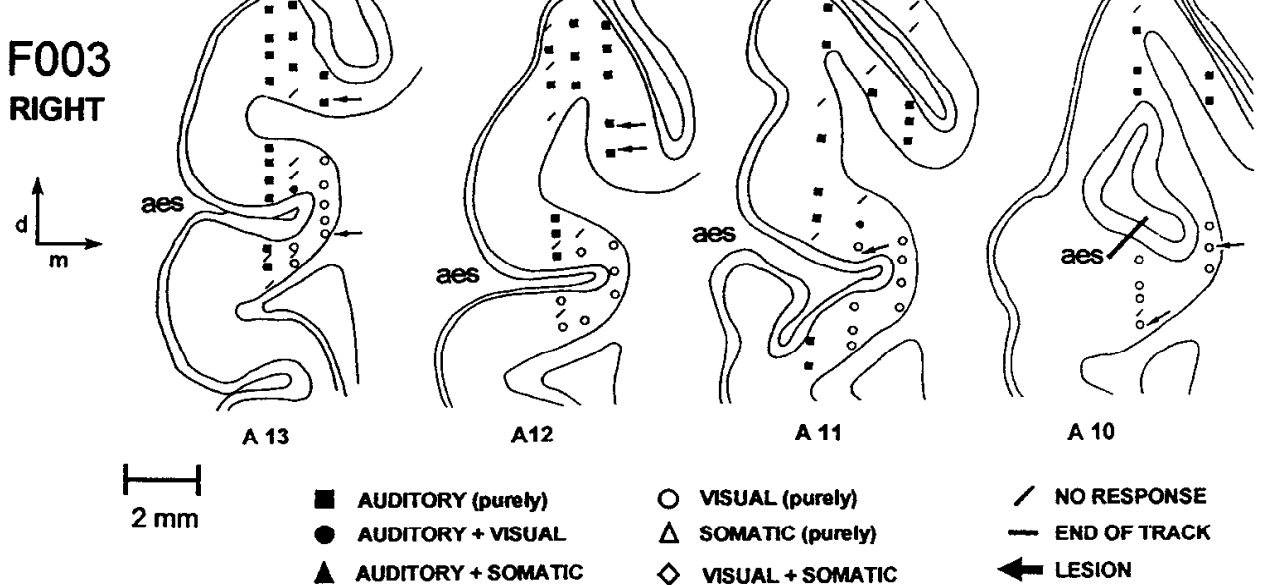

Figure 2. Frontal sections through four cerebral hemispheres in normal adult cats with reconstruction of electrode penetrations. Numbers on top of each column of sections refer to different frontal planes as in Figure $1 C$. Stereotaxic coordinates in the anteroposterior dimension are given beneath each section. $d$, dorsal; $m$, medial. Neurons in the AE sulcal region were sampled at constant intervals of $250 \mu \mathrm{m}$. Only 11 of 318 neurons were found to be bimodal, nine of them responding to auditory and visual, two to visual and somatosensory stimulation. aes, AE sulcus; sss, suprasylvian sulcus. 
expansion contraction

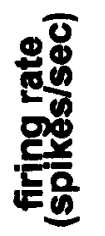

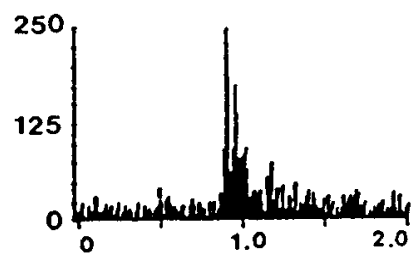

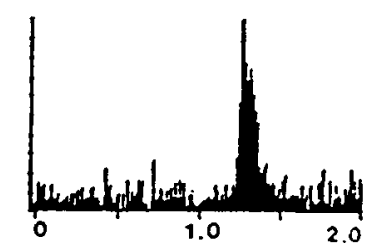

rotation clockwise

\section{rotation counterclockwise}
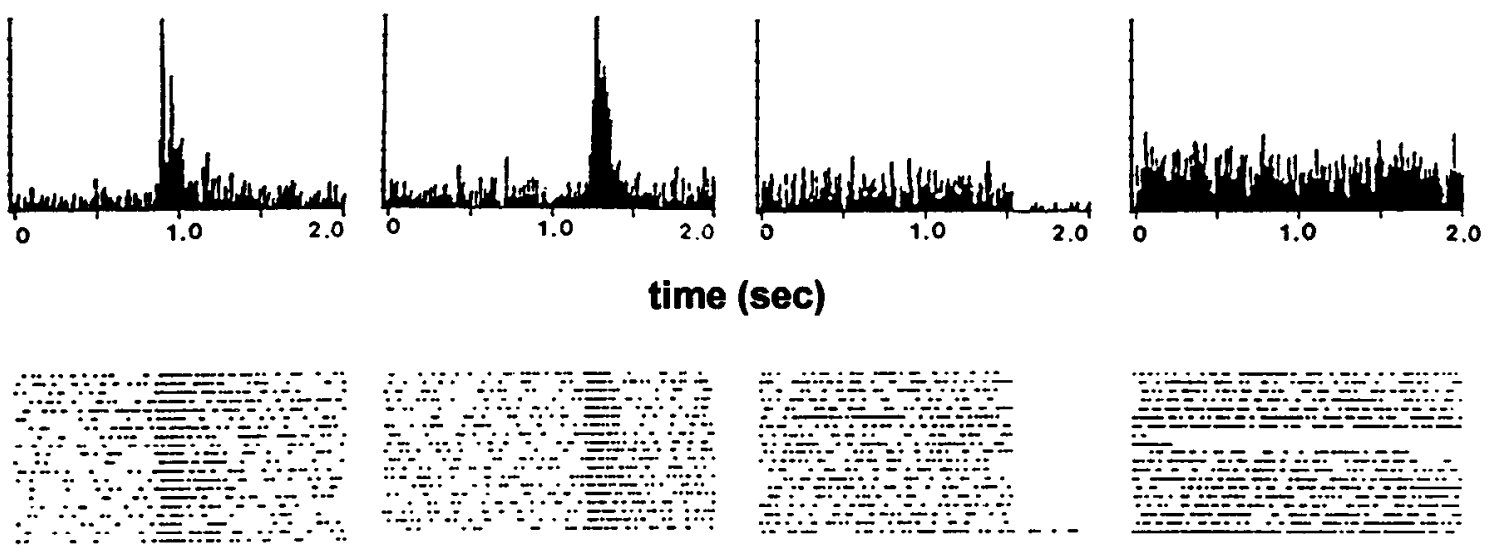

time (sec)

Figure 3. Visual response of a typical neuron in the AEV of a normal cat. PSTHs and their associated raster displays after 20 stimulus repetitions are shown to demonstrate the briskness and selectivity of responses in AEV. Spontaneous discharge rate can be assessed from the initial 500 msec of the PSTH. Visual stimuli consisted of large-field optic flow stimuli $\left(100 \times 70\right.$ degrees $\left.^{2}\right)$ that were projected on a screen. The two panels to the left show the responses to radially moving flow-field stimuli (expansion, contraction). For the two panels to the right the flow field was rotating clockwise and counterclockwise, respectively. Many cells preferred radial (expanding or contracting) stimuli.

are shown in Figure 2. Several clear-cut findings can be recognized. First, multimodal responses in this part of the AE cortcx are rare. Second, visual neurons are restricted to the ventral bank and fundus of the AE sulcus, as previously reported (AEV; Mucke et al., 1982; Olson and Graybiel, 1983, 1987). Neurons responded briskly to visual stimulation; the response of a typical neuron is shown in Figure 3. Third, somatosensory responses are rarely encountered in this caudal part of the AE sulcus. However, they were more frequent rostrally (A13-A18). Finally, auditory neurons are found on both banks of the AE sulcus
(AEA; "field AES" of Clarey and Irvine, 1990a) as well as in the AE gyrus (corresponding to the AAF). Cells in AEA are more broadly tuned to frequency than cells in AAF and usually respond better to complex sounds than to pure tones: among 55 neurons in which the response to tone bursts and complex sounds was compared, $42(76 \%)$ clearly responded better to the complex sounds. Of those cells that responded to tones and whose frequency tuning could be determined $(n=27), 78 \%$ showed broad tuning. No evidence for tonotopy in AEA was found. These findings confirm the results of Clarey and Irvine

\section{Normal Vision}

Figure 4. Sensory modality distributions of neuronal responses in the AES of individual normal cats. Mutually exclusive categories are formed by counting unimodal ( $a u d$, auditory; vis, visual; som, somatosensory) and bimodal neurons separately. $N C R$, no clear response to any of the stimuli tested. A large number of neurons with purely visual responses is found in the AEV subdivision of the $\mathrm{AE}$ sulcus. Bimodal cells are relatively rare.
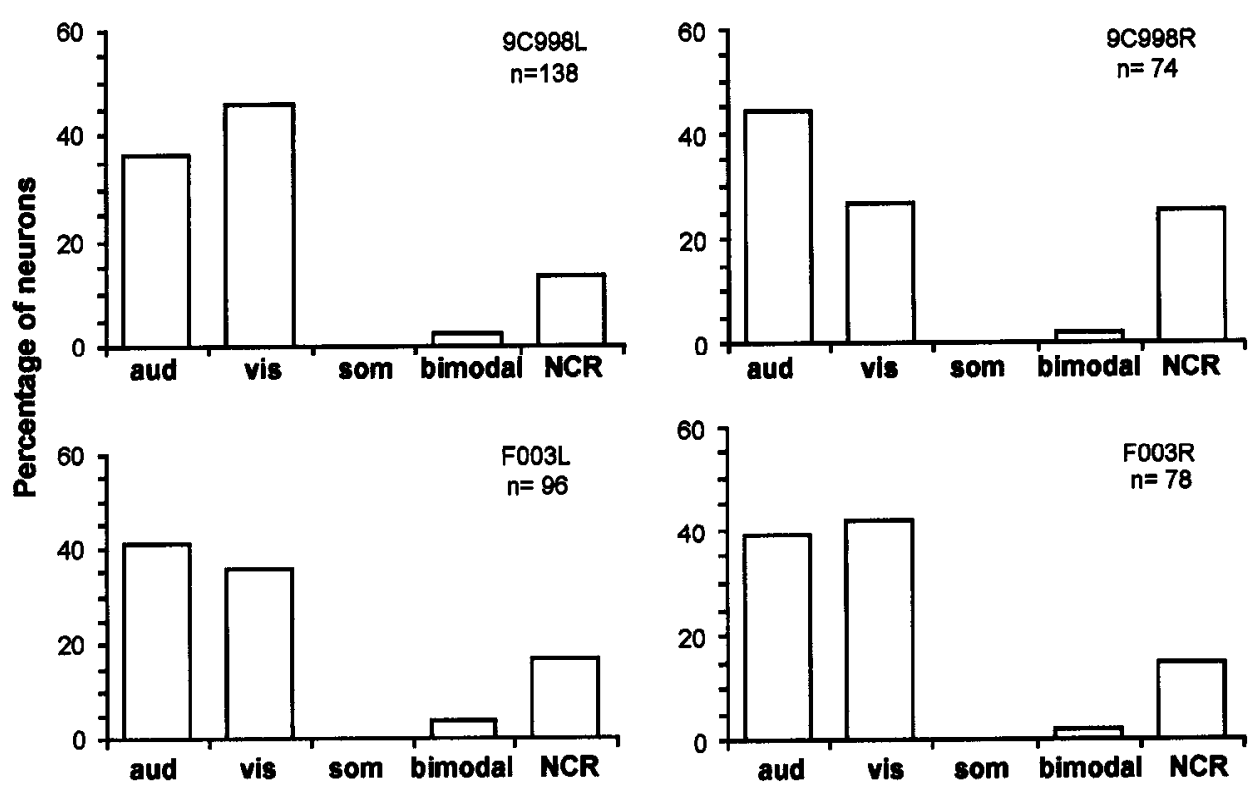

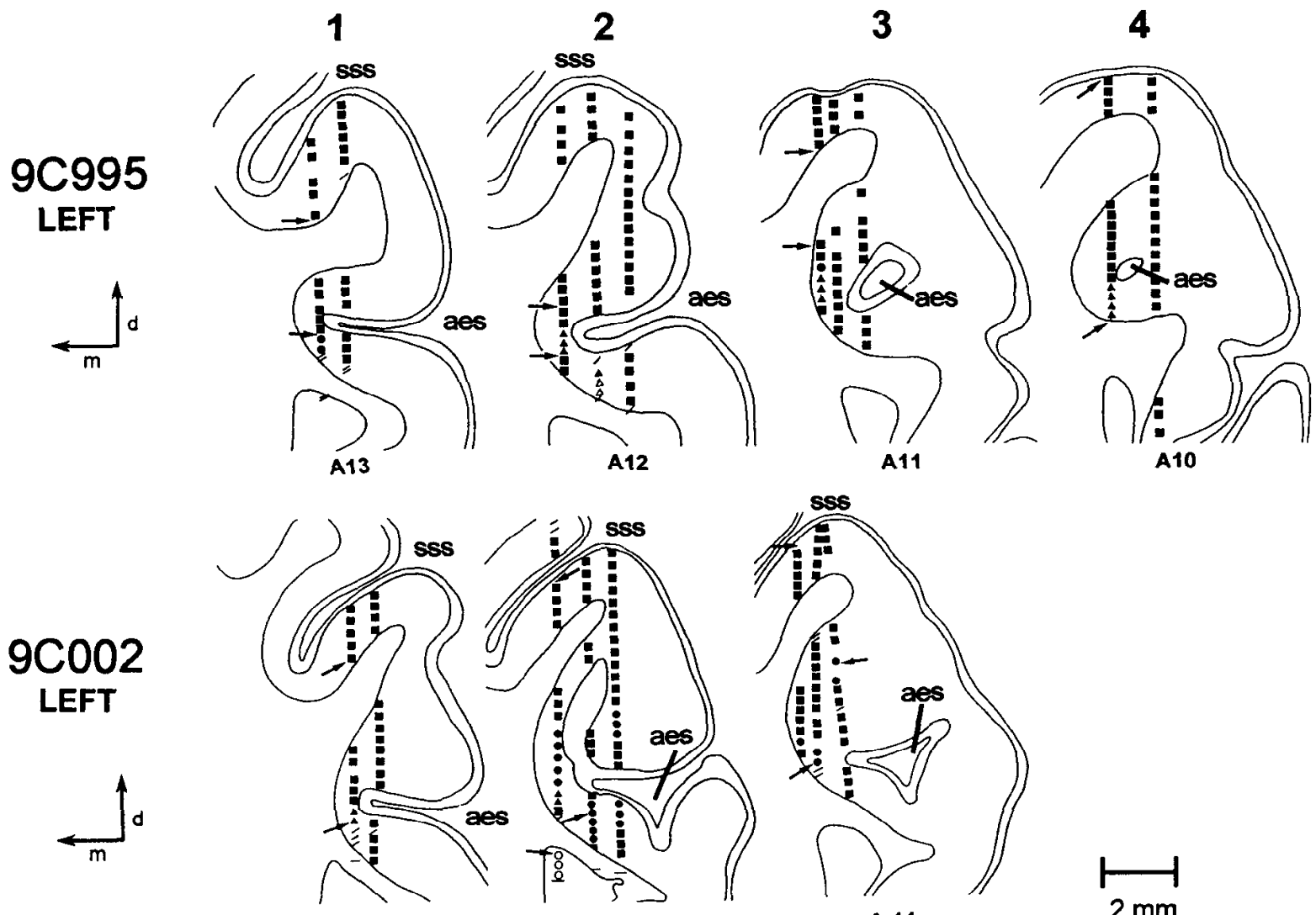

A 11
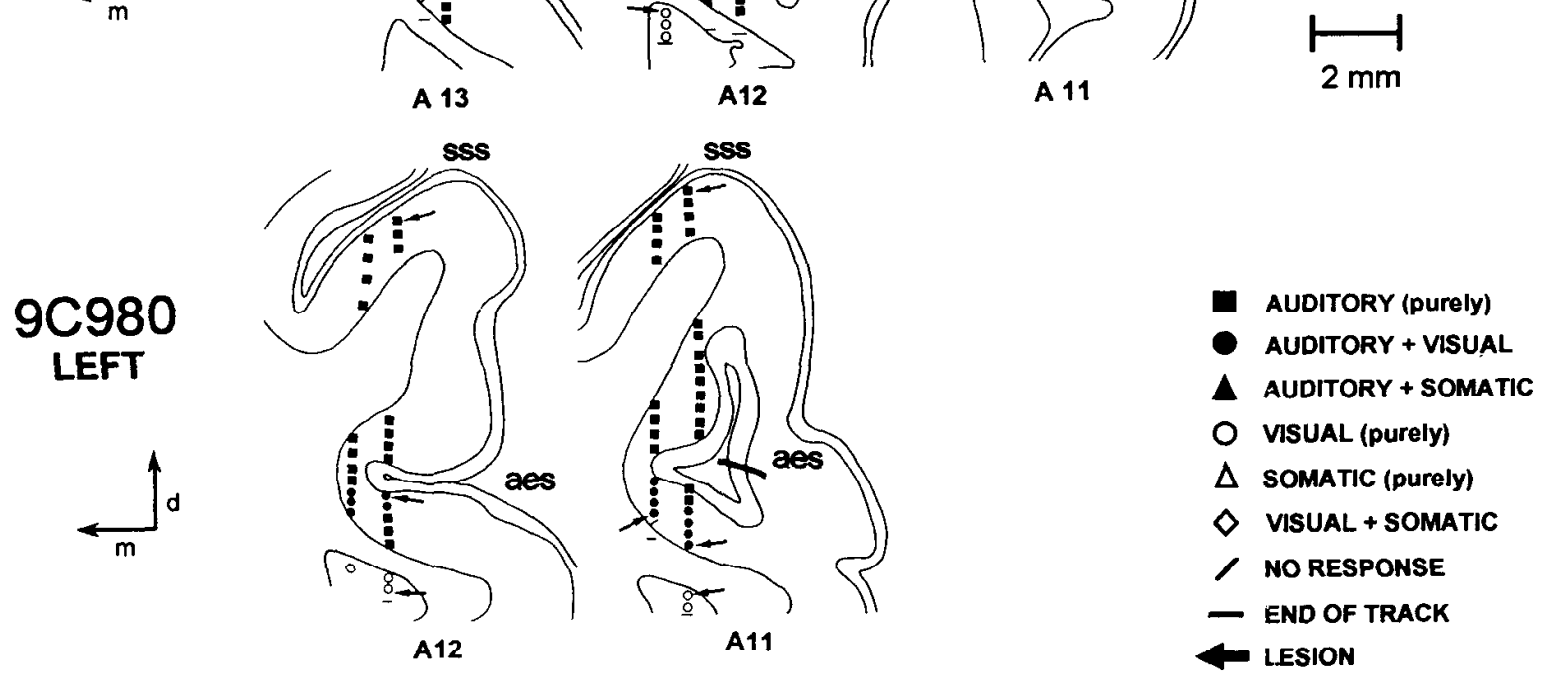

Figure 5. Frontal sections through the left cerebral hemispheres of three cats with BD from birth and reconstruction of electrode penetrations. Planes of section $(1-4)$ are as in Figure $1 C$. Conventions and symbols are as in Figure 2. Fifty-three of 239 neurons (22\%) were bimodal in BD cats, 29 responding to auditory and visual, 21 to auditory and somatosensory, and 3 to visual and somatosensory stimulation. No trimodal units were found.

(1990a), and on these grounds AEA can be delimited from AAF fairly easily.

The proportions of neurons in the AE sulcal region responding to different sensory modalities were then determined from the reconstructed electrode tracks. Neurons in the AE gyrus consistently responded only to auditory stimuli in both groups of animals and were not included in the following analysis. On the basis of the functional criteria described above and in other studies (Knight, 1977; Tian and Rauschecker, 1992) it was clear that these cells were part of AAF. Their exclusion was further facilitated by the track reconstructions (Fig. 2). In all medial penetrations, gyral and sulcal regions were separated by white matter. For more lateral electrode tracks, where this was not the case, a strict rule was established on top of the functional criteria, which defined all neurons more than $2 \mathrm{~mm}$ from the pial surface of the sulcus as part of the AE gyrus. The combination of these two criteria virtually guaranteed that no AAF neurons were included in our sample, and the analysis was restricted to the AE sulcal region. It should be emphasized that our basic result does not depend on whether AAF neurons are included; we simply feel that, from a functional standpoint, it would not be correct to include data from this purely auditory area in the present analysis.

The percentages of cells in the caudal AE sulcal region re- 
A
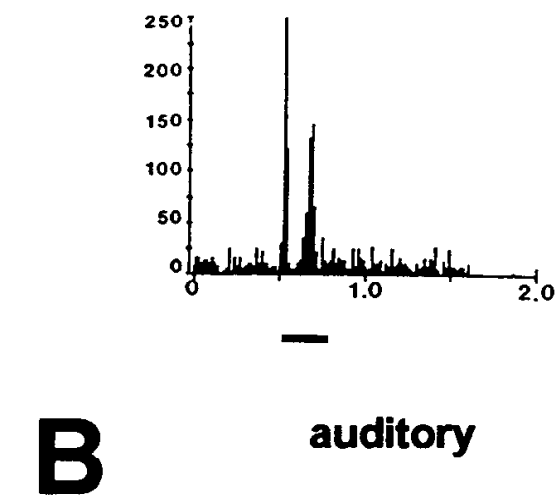

auditory

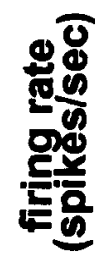

auditory
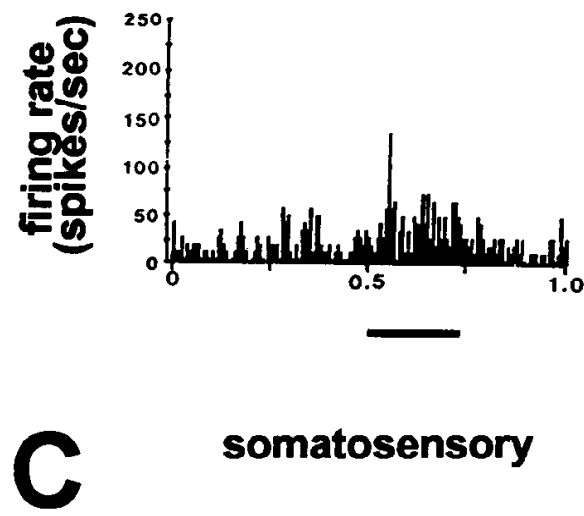

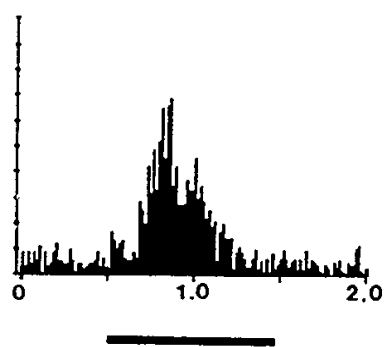

somatosensory

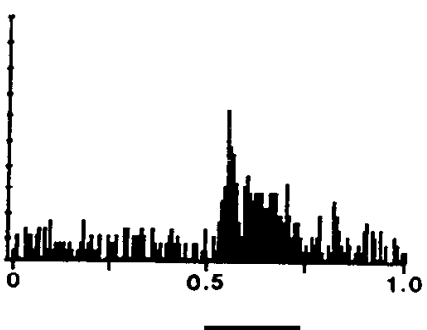

visual

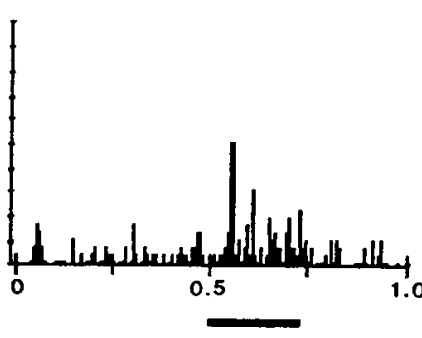

time (sec) auditory

(repeat)

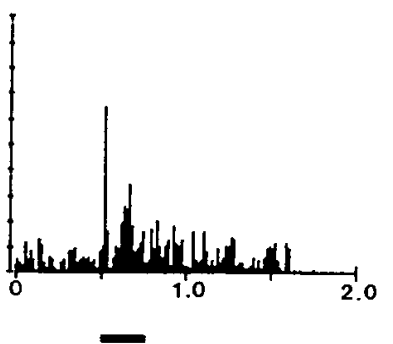

auditory

(repeat)

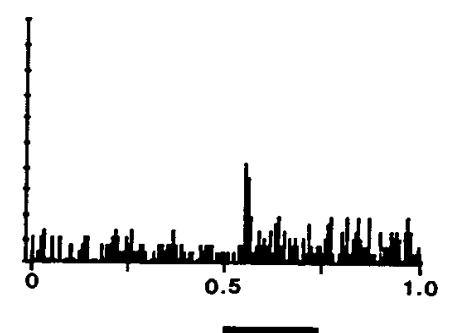

somatosensory (repeat)

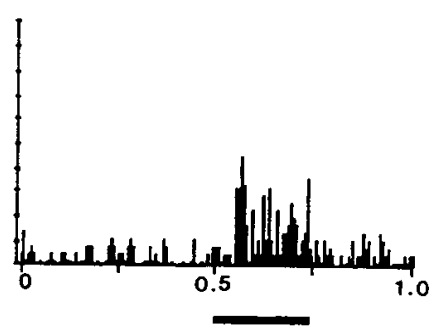

Figure 6. Typical bimodal responses from threc single neurons $(A-C)$ in the AE sulcus of BD cats. Responses are shown as PSTHs after 20 trials. Stimulus onset in each case happened after a pretrial interval of $500 \mathrm{msec}$, as shown by horizontal bars, in order to assess spontaneous discharge rate. While in normal cats bimodal responses were rare, clear evidence for input from two or more modalities (mostly including the auditory one) was found in BD cats. In all cases, stimulation in both modalities was repeated in a second block with the same or slightly modified stimuli, in order to verify the stability of responses. Auditory responses were far better to natural complex sounds, standardized and delivered by a digital system (see Materials and Methods), than to pure tones. Preferred visual stimuli were large and diffuse. $A$, Neuron responding briskly to both auditory and visual stimulation. The preferred auditory stimulus was a digitized finger snap (67 dB SPL, re $20 \mu \mathrm{Pa}$ ). The visual stimulus was a large $\left(15^{\circ}\right)$ spot of light moving down across the visual field. $B$, Neuron responding to auditory and somatosensory stimuli. The auditory stimulus was the same as in $A$. The cell had a clearly defined somatosensory receptive field on the contralateral foreleg and responded to light touch or airpuff stimulation. $C$, Neuron responding briskly to somatosensory and visual stimulation. The preferred somatosensory stimulus was light touch of a particular whisker on the contralateral face. Preferred visual stimuli were $>20^{\circ}$.

sponding to stimuli with different sensory modalities and of those with NCR are given in Figure 4. Out of a total of 386 neurons in this part of the AE sulcus, 68 (17.6\%) did not respond to any of our stimuli. Of those that were responsive, $96.5 \%(307$ of 318 ) were unimodal; only $3.5 \%$ (11 of 318$)$ were bimodal.

\section{Modality changes in the $A E$ sulcus of $B D$ cats}

In BD cats, sensory modality was determined in 532 neurons of the caudal $\mathrm{AE}$ region, 303 of which were located in the $\mathrm{AE}$ sulcus. Neurons in the AE gyrus corresponding to AAF, as defined above for the normal controls, were excluded from the analysis. Electrode track reconstructions from BD cats are shown in Figure 5. They differ from those of normal cats in several respects. First, visual responses are significantly reduced. Few, if any, cells with a purely visual response are present in the ventral bank and fundus of the AE sulcus or elsewhere. Any visual neurons that are still encountered in this area virtually always have an additional auditory input. 


\section{Binocular Deprivation}
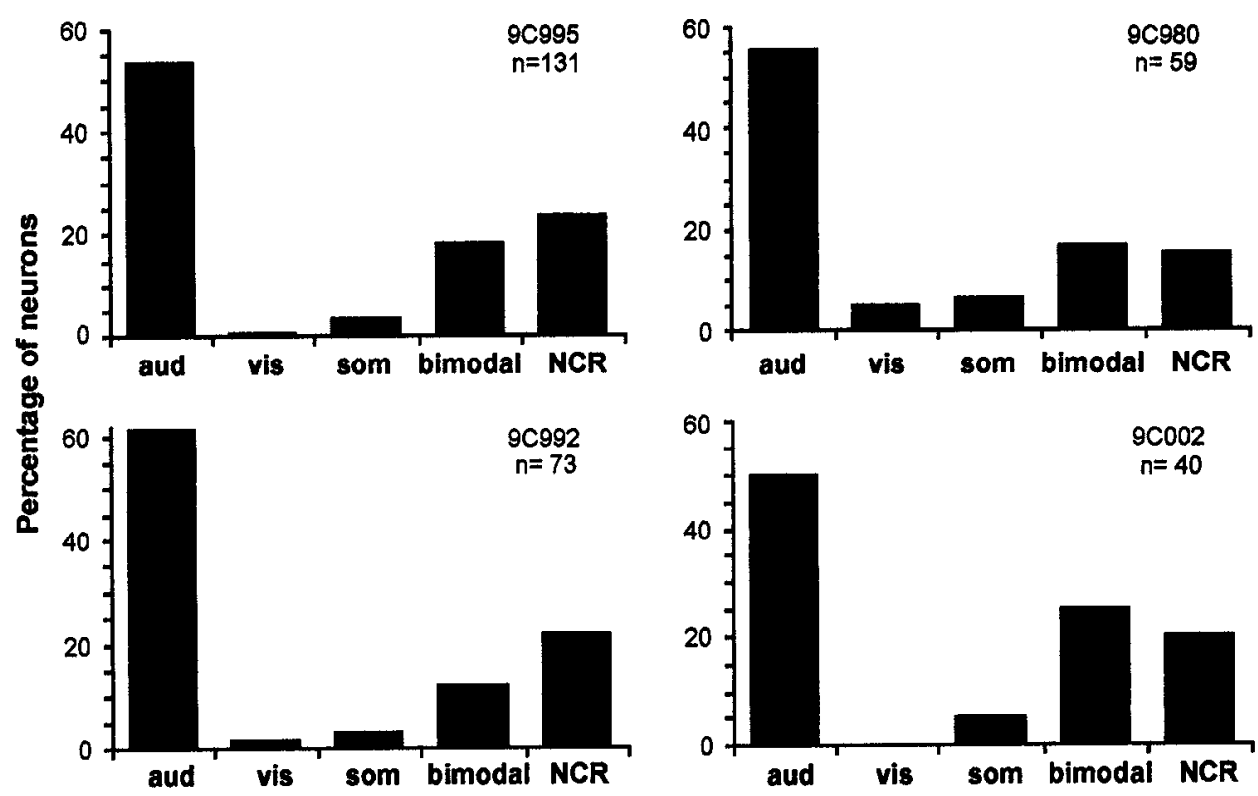

Figure 7. Sensory modality distributions of neuronal responses in the $\mathrm{AE}$ sulcus of individual BD cats. Conventions are as in Figure 4. Visual responses are almost entirely eliminated in the AE sulcal region of BD cats, while the proportion of auditory responses is increased accordingly. Bimodal responses are also more frequent in BD than in normal cats. No significant increase of unresponsive neurons is found in any of the BD cats.

While the lack of visual responsiveness was not totally unexpected in view of the severely reduced responsiveness in the striate cortex of BD cats (Wiesel and Hubel, 1965; Singer and Tretter, 1976), the second major finding did come as a surprise to us: unlike in striate cortex, only very few unresponsive neurons were encountered. Rather, in the same region of the $\mathrm{AE}$ cortex where visual cells had been found in control cats, auditory and, to a lesser extent, somatosensory responses were now abundant. In addition, the amount of multimodal convergence was significantly higher. Clear examples of bimodal responses are shown in Figure 6 . The results from individual BD cats are displayed in Figure 7. Altogether, 64 of 303 neurons (21.1\%) were unresponsive (NCR), $77.8 \%$ (186 of 239) gave unimodal responses, and $22.2 \%$ (53 of 239 ) gave bimodal responses.

The modality distributions from normal and $\mathrm{BD}$ cats in the caudal part of the AE sulcus can be compared more directly in Figure 8, which summarizes the principal group results: compared to normal controls, BD cats have (1) a smaller proportion of visually responsive neurons $\left(\chi^{2}=183.8, p<0.0001, \chi^{2}\right.$ test $)$, (2) an increased proportion of auditory neurons $\left(\chi^{2}=21.8, p\right.$ $<0.0001$ ), (3) a significant proportion of neurons with somatosensory responses $\left(\chi^{2}=20, p<0.0001\right)$, (4) many more bimodal units, especially such with an auditory input $\left(\chi^{2}=44.7\right.$, $p<0.0001)$, and (5) an unchanged proportion of unresponsive neurons $\left(\chi^{2}=1.9, p>0.1\right)$.

\section{Discussion}

\section{Multimodality of the $A E$ sulcus in normal and visually} deprived cats

The principal finding of this study is that in a region of cat cortex in which visual responses normally predominate, area AEV in the AE sulcus (Mucke et al., 1982; Olson and Graybiel, 1983), most neurons become briskly responsive to nonvisual stimuli after long-term BD from birth. Furthermore, a higher proportion of bimodal neurons is found in the AE sulcus of BD animals. This raises questions about the extent of overlap that normally exists in this part of the cortex between inputs from different sensory modalities and the degree of convergence onto single neurons.

The issue of multisensory convergence in the AE sulcal region has been a matter of some controversy in the past. While it is undisputed that neurons responsive to different sensory modalities can be found in neighboring regions within the AE sulcus, it is not clear if these different modalities exist (1) in separate areas (Mucke et al., 1982; Clemo and Stein, 1983; Olson and Graybiel, 1983, 1987; Meredith and Clemo, 1989), (2) in largely unimodal clusters within the same areas (Clarey and Irvine, 1986, 1990a), or (3) as single neurons with multimodal input (Berman, 1961; Minciacchi et al., 1987; Jiang et al., 1990). Our data from normal animals seem to support the first possibility (predominantly unimodal areas), but do not exclude input from other modalities that remain subthreshold under our recording conditions. Indeed, some of the studies that found high proportions of intermingled unit responses in the AE sulcal region (e.g., Clarey and Irvine, 1990a) used chloralose anesthesia, which is known to reveal subliminal input. In addition, different electrodes or recording techniques may contribute to the discrepancy in results. It is important to note, however, that the difference between normal and BD cats in our study cannot be explained by any of these factors, because identical techniques were used in all animals.

\section{Mechanisms of compensatory plasticity}

The existence of subthreshold input could provide a convenient mechanism for an increase of nonvisual and multimodal responsiveness in the AE sulcal region of visually deprived cats, because it would require only a modification of existing synaptic input. Such changes in the efficacy of Hebb-type synaptic connections have been postulated previously as the basis for developmental plasticity in primary visual cortex (Rauschecker and Singer, 1981; Frégnac and Imbert, 1984; Rauschecker, 1991). It appears conceivable that similar rules could allow plastic 

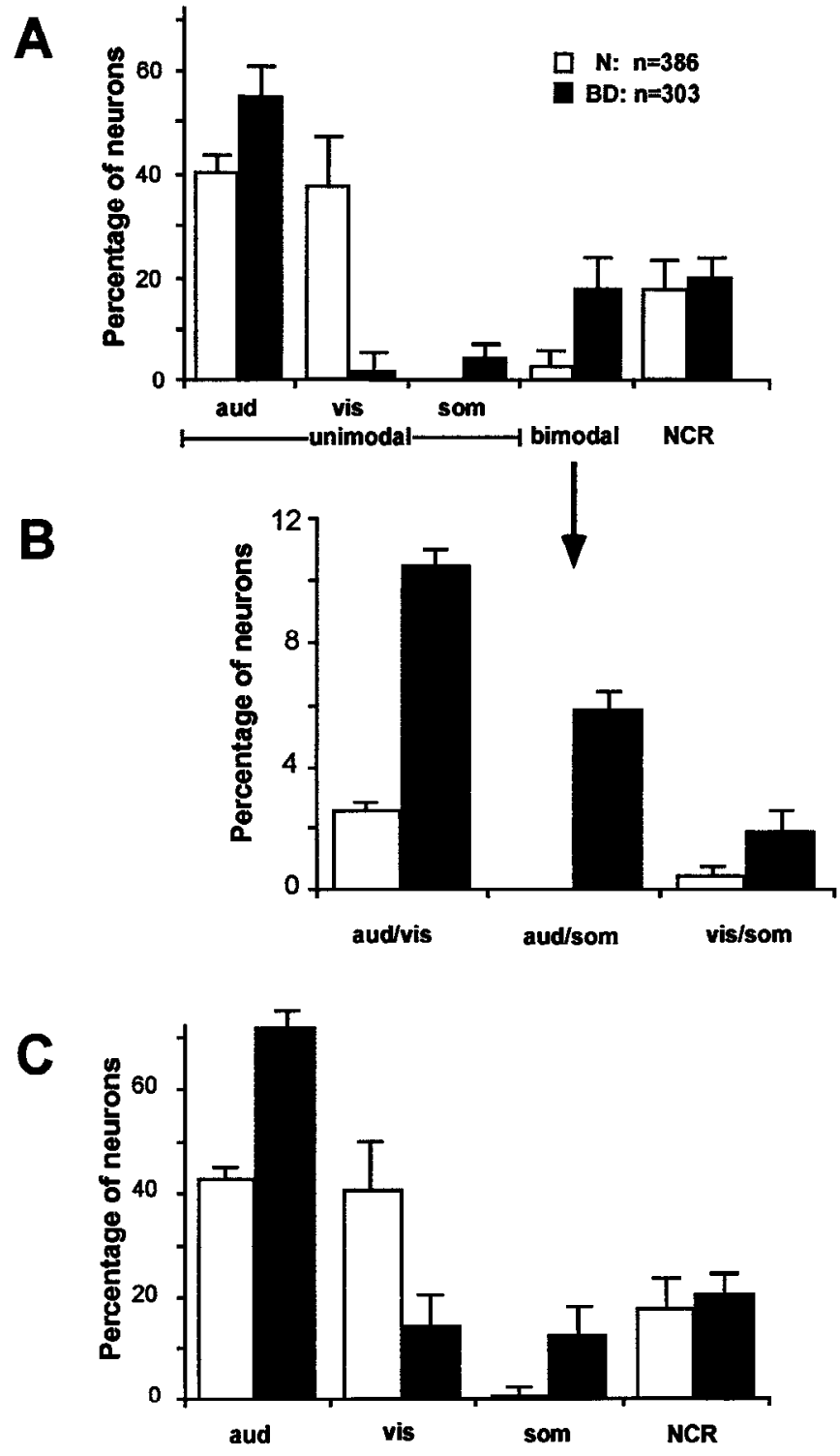

Figure 8. Direct comparison of sensory modality distributions in normal and BD groups. Mean percentages (with standard deviations) of neurons responsive to stimuli of a certain sensory modality are displayed. Total number of neurons in each group is given in the legend. Open blocks, normal cats; solid blocks, $\mathrm{BD}$ cats. $A$, Distribution of all neurons with exclusive categories; that is, unimodal and bimodal neurons are displayed separately, as in Figures 4 and 7 (same conventions). $B$, Distribution of bimodal neurons alone with different combinations of sensory responses. $C$, Distribution of all neurons with overlapping categories; that is, bimodal neurons contribute twice, which leads to a total of more than $100 \%$, when columns are added up for each group.

changes throughout neocortex during early postnatal development or even beyond. Depending on sensory-driven activity, certain inputs would be maintained or strengthened, while others would recede or fail to develop. It is entirely possible that the amount of multimodal convergence changes even during normal development: while a kitten may be born with a high amount of multimodal convergence, predominantly unimodal territories may get carved out by cross-modal competition later. In such a model, visual deprivation would disturb the input balance to the AE sulcal region during development and provide a better chance for the survival of existing nonvisual inputs.
As an alternative to this notion, the cross-modal intrusion of formerly visual territory by functional nonvisual input has to be considered. At first sight, the following would seem to speak against this possibility: we found a significant number of brisk somatosensory responses in this rather caudal part of the $\mathrm{AE}$ sulcal region (between A10 and A13) in BD cats. Generally, somatosensory neurons have been reported for more rostral positions, between A15 and A18 (Carreras and Andersson, 1963; area S IV of Clemo and Stein, 1983). Any growth of somatosensory axons, therefore, would have to occur over a distance of several millimeters. However, comparable within-modality expansions have been postulated recently in the somatosensory cortex of adult monkeys after deafferentation (Pons et al., 1991). The possibility of a cross-modal invasion of AEV as a result of visual deprivation, therefore, cannot be discounted.

No increase in the proportion of unresponsive neurons was found in $\mathrm{BD}$ cats, nor did we encounter any silent areas along the electrode tracks. This suggests that, regardless of which of the above two mechanisms is responsible, existing visual inputs were replaced or supplemented by nonvisual inputs as a result of cross-modal competition. In striate cortex, the proportion of visually unresponsive neurons is vastly increased after longterm binocular eyelid suture (Wiesel and Hubel, 1965; Singer and Tretter, 1976). There is no evidence that any of these neurons become responsive to nonvisual stimuli. The changes in AE cortex described in the present study are therefore unlikely to originate at these more peripheral levels. The absence of a substantial auditory or somatosensory input to primary visual areas may preclude extensive modality changes in these regions, even though a transitory projection from auditory to visual cortex has been reported in neonatal cats (Innocenti and Clarke, 1984).

Other cases of cross-modal plasticity have been reported in the past, but only after drastic interventions. If their normal target structures are surgically removed, optic tract fibers can be rerouted to auditory or somatosensory thalamus, rendering neurons there and in the corresponding cortices responsive to visual stimuli (Métin and Frost, 1989; Roe et al., 1990). These and other studies demonstrate that the fate of a cortical region is not necessarily predetermined, but can be changed by epigenetic factors (Rakic, 1988; Schlaggar and O'Leary, 1991). Different cortical areas may thus be very similar in their structure and function, regardless of which sensory modality they serve in normal animals, which permits them to serve the functions of other modalities in experimentally manipulated animals.

\section{Relationship between $A E$ cortex and tectum}

An increase in the proportion of auditory neurons similar to the one we report here for the AF cortical region has been described previously for the SC in the midbrain tectum of visually deprived cats (Rauschecker and Harris, 1983) and rats (Vidyasagar, 1978). Area AEA provides the strongest auditory cortical input to the SC (Meredith and Clemo, 1989; Clarey and Irvine, 1990b), and the corticotectal projection from the $\mathrm{AE}$ region to the $\mathrm{SC}$ is strengthened even further in visually deprived cats (J. P. Rauschecker and A. Aschoff, unpublished observations). It is conceivable, therefore, that the augmentation of auditory responses in the SC of BD animals is secondary to the changes in the $\mathrm{AE}$ region described here.

There are reasons to believe that the $\mathrm{AE}$ region, like the $\mathrm{SC}$, is involved in intermodal or modality-independent orienting behavior (Wallace et al., 1992). AEV receives its main cortical 
input from the lateral suprasylvian areas (Norita et al., 1986; Olson and Graybiel, 1987), for which a role in the processing of optic flow from ego-motion has been suggested (Rauschecker et al., 1987; Brenner and Rauschecker, 1990; Lappe and Rauschecker, 1993). The neurons in the present study responsive to radially expanding or contracting flow-field stimuli seem to be compatible with a role of AEV in such visuospatial behavior. Similarly, one may argue that the auditory areas in the AE region (AAF and AEA) could be part of an auditory spatial processing stream, because neurons in these areas react best to fast transient sounds and have a fair proportion of spatially tuned cells among them (Rauschecker et al., 1993).

\section{Auditory compensation for early blindness in different species}

The rise in the number of auditory neurons in AE cortex could provide a neural basis for the improvements of behavioral performance in auditory localization that we have seen in visually deprived cats (Rauschecker and Kniepert, 1987). It is clear from these results that early vision loss does not necessarily result in a concomitant deterioration of other sensory functions, but on the contrary can lead to their compensatory improvement. Similar conclusions have recently been drawn for the tactile compensation observed in early blind mice, where an expansion of the somatosensory whisker barrel field is found after binocular enucleation (Rauschecker et al., 1992). From both studies it becomes evident that such compensation is not just a matter of increased attention, different strategies, or "higher learning," but involves changes in the circuitry of cortical networks. In both cases, a significant expansion of cortical tissue devoted to the processing of nonvisual functions after early blindness can be measured with physiological and anatomical methods.

An improvement of higher auditory functions in blind humans has been claimed as early as the last century (Griesbach, 1899), as well as later (Seashore and Ling, 1918; Kellogg, 1962; Niemeyer and Starlinger, 1981). However, an almost equal number of skeptical reports pointing to a general degradation of higher sensory functions, especially of space perception, in the blind has also been published (Worchel, 1951; Axelrod, 1959; Hartlage, 1976). Two studies specifically examined the auditory spatial functions of early blind humans: while one group found a clear improvement of auditory capabilities (Rice et al., 1965; Rice, 1970), another found no change or even a slight deterioration (Spigelman, 1978). In the light of our present results of an expanded auditory cortical representation in early blind cats, these human studies merit reevaluation.

\section{References}

Axelrod S (1959) Effects of early blindness. New York: American Foundation for the Blind.

Benedek G, Mucke L, Norita M, Albowitz B, Creutzfeldt OD (1988) Anterior ectosylvian visual area (AEV) of the cat: physiological properties. Prog Brain Res 75:245-255.

Berman AL (1961) Interaction of cortical responses to somatic and auditory stimuli in anterior ectosylvian gyrus of cat. J Neurophysiol 24:608-620.

Blakemore C, Cooper GF (1970) Development of the brain depends on the visual environment. Nature 228:477-478.

Brenner E, Rauschecker JP (1990) Centrifugal motion bias in the cat's lateral suprasylvian visual cortex is independent of early flow field exposure. J Physiol (Lond) 423:641-660.

Carlson S, Pertovaara A, Tanila H (1987) Late effects of early binocular visual deprivation on the function of Brodmann's area 7 of monkeys (Macaca arctoides). Dev Brain Res 33:101-111.

Carreras M, Andersson SA (1963) Functional properties of neurons of the anterior ectosylvian gyrus of the cat. J Neurophysiol 26:100126.

Clarey JC, Irvine DRF (1986) Auditory response properties of neurons in the anterior ectosylvian sulcus of the cat. Brain Res 386:12-19.

Clarey JC, Irvine DRF (1990a) The anterior ectosylvian sulcal auditory field in the cat: I. An electrophysiological study of its relationship to surrounding auditory cortical fields. J Comp Neurol 301:289-303.

Clarey JC, Irvine DRF (1990b) The anterior ectosylvian sulcal auditory field in the cat: II. A horseradish peroxidase study of its thalamic and cortical connections. J Comp Neurol 301:304-324.

Clemo HR, Stein BE (1983) Organization of a fourth somatosensory area of cortex in the cat. J Neurophysiol 50:910-923.

Frégnac Y, Imbert M (1984) Development of neuronal selectivity in the primary visual cortex of the cat. Physiol Rev 64:325-434.

Griesbach H (1899) Vergleichende Untersuchungen über die Sinnesschärfe Blinder und Sehender. Pfluegers Arch 74:577-638.

Hartlage LC (1976) Development of spatial concepts in visually deprived children. Percept Mot Skills 42:255-258.

Hyvärinen J, Carlson S, Hyvärinen L (1981) Early visual deprivation alters modality of neuronal responses in area 19 of monkey cortex. Neurosci Lett 4:239-243.

Innocenti GM, Clarke S (1984) Bilateral transitory projection from auditory cortex in kittens. Dev Brain Res 14:143-148.

Jiang H, Leporé F, Ptito M, Guillemot J-P (1990) Modality specificity of neuronal responses in the anterior ectosylvian cortex (AEC) of cats. Soc Neurosci Abstr 16:1221.

Kellogg WN (1962) Sonar system of the blind. Science 137:399-404.

Knight PL (1977) Representation of the cochlea within the anterior auditory field (AAF) of the cat. Brain Res 130:447-467.

Lappe M, Rauschecker JP (1993) A neural network for the processing of optic flow from ego-motion in man and higher mammals. Neural Comput 5:374-391.

Meredith MA, Clemo HR (1989) Auditory cortical projection from the anterior ectosylvian sulcus (field AES) to the superior colliculus in the cat: an anatomical and electrophysiological study. J Comp Neurol 289:687-707.

Merzenich MM, Colwell SA, Andersen RA (1982) Auditory forebrain organization. Thalamocortical and corticothalamic connections in the cat. In: Cortical sensory organization, Vol 3, Multiple auditory areas (Woolsey CN, ed), pp 43-57. Clifton, NJ: Humana.

Métin C, Frost DO (1989) Visual responses of neurons in somatosensory cortex of hamsters with experimentally induced retinal projections to somatosensory thalamus. Proc Natl Acad Sci USA 86:357361.

Minciacchi D, Tassinari G, Antonini A (1987) Visual and somatosensory integration in the anterior ectosylvian cortex of the cat. Brain Res 410:21-31.

Mucke L, Norita M, Benedek G, Creutzfeldt OD (1982) Physiologic and anatomic investigation of a visual cortical area situated in the ventral bank of the anterior ectosylvian sulcus of the cat. Exp Brain Res 46:1-11.

Niemeyer W, Starlinger I (1981) Do the blind hear better? Investigations on auditory processing in congenital or early acquired blindness. II. Central functions. Audiology 20:510-515.

Norita M, Mucke L, Benedek G, Albowitz B, Katoh Y, Creutzfeldt OD (1986) Connection of the anterior ectosylvian visual area (AEV). Exp Brain Res 62:225-240.

Olson CR, Graybiel AM (1983) An outlying visual area in the cerebral cortex of the cat. Prog Brain Res 58:239-245.

Olson CR, Graybiel AM (1987) Ectosylvian visual area of the cat: location, retinotopic organization, and connections. J Comp Neurol 261:277-294.

Pettigrew JD (1978) The paradox of the critical period for striate cortex. In: Neuronal plasticity (Cotman CW, ed), pp 311-330. New York: Raven.

Pons TP, Garraghty PE, Ommaya AK, Kaas JH, Taub E, Mishkin M (1991) Massive cortical reorganization after sensory deafferentation in adult macaques. Science 252:1857-1860.

Rakic P (1988) Specification of cerebral cortical areas. Science 241: $170-176$.

Rauschecker JP (1991) Mechanisms of visual plasticity: Hebb synapses, NMDA receptors, and beyond. Physiol Rev 71:587-615.

Rauschecker JP, Harris LR (1983) Auditory compensation of the effects of visual deprivation in the cat's superior colliculus. Exp Brain Res 50:69-83. 
Rauschecker JP, Kniepert U (1987) Auditory localization behavior in cats deprived of vision. Soc Neurosci Abstr 13:871.

Rauschecker JP, Korte M (1992) Auditory compensation of early visual deprivation in the cat's anterior ectosylvian cortex. Soc Neurosci Abstr 18:593.

Rauschecker JP, Singer W (1981) The effects of early visual experience on the cat's visual cortex and their possible explanation by Hebb synapses. J Physiol (Lond) 310:215-239.

Rauschecker JP, von Grünau MW, Poulin C (1987) Centrifugal organization of direction preferences in the cat's lateral suprasylvian visual cortex and its relation to flow field processing. J Neurosci 7:943-958.

Rauschecker JP, Tian B, Korte M, Egert U (1992) Crossmodal changes in the somatosensory vibrissa/barrel system of visually deprived animals. Proc Natl Acad Sci USA 89:5063-5067.

Rauschecker JP, Tian B, Korte M (1993) Spatial tuning of single neurons in the anterior auditory areas (AAF and AEA) of the cat's cortex. ARO Abstr 16:109.

Reinoso-Suárez F, Roda JM (1985) Topographical organization of the cortical afferent connections to the cortex of the anterior ectosylvian sulcus in the cat. Exp Brain Res 59:313-324.

Rice CE (1970) Early blindness, early experience, and perceptual enhancement. Res Bull Am Found Blind 22:1-22.

Rice CE, Feinstein SH, Schusterman RJ (1965) Echo-detection ability of the blind: size and distance factor. J Exp Psychol 70:246-251.

Roe AW, Pallas SL, Hahm J, Sur M (1990) A map of visual space induced in primary auditory cortex. Science 250:818-820.

Schlaggar BL, O'Leary DMM (1991) Potential of visual cortex to develop an array of functional units unique to somatosensory cortex. Science 252:1556-1559.
Seashore CE, Ling TL (1918) The comparative sensitiveness of blind and seeing persons. Psychol Monogr 25:148-158.

Singer W, Tretter F (1976) Receptive-field properties and neuronal connectivity in striate and parastriate cortex of contour-deprived cats. J Neurophysiol 39:613-630.

Spigelman MN (1978) A comparative study of the effects of early blindness on the development of auditory-spatial learning. In: The effects of blindness and other impairments on early development (Jastrzembska ZS, ed), pp 29-45. New York: American Foundation for the Blind.

Stryker MP, Sherk H, Leventhal AG, Hirsch HVB (1978) Physiological consequences for the cat's visual cortex of cffcctivcly restricting early visual experience with oriented contours. J Neurophysiol 41: 896-909.

Tian B, Rauschecker JP (1992) Neuronal responses to frequency modulated sounds in the anterior auditory field (AAF) of the cat's cortex. Soc Neurosci Abstr 18:843.

Vidyasagar TR (1978) Possible plasticity in the rat superior colliculus. Nature 275:140-141.

Wallace MT, Meredith MA, Stein BE (1992) Integration of multiple sensory modalities in cat cortex. Exp Brain Res 91:484-488.

Wiesel TN, Hubel DH (1963) Single-cell responses in striate cortex of kittens deprived of vision in one eye. J Neurophysiol 26:10031017.

Wiesel TN, Hubel DH (1965) Comparison of the effects of unilateral and bilateral eye closure on cortical unit responses in kittens. J Neurophysiol 28:1026-1040.

Worchel P (1951) Space perception and orientation in the blind. Psychol Monogr 65:1-28. 